\title{
Aspectos de qualidade da água e saneamento básico em um assentamento rural no interior de São Paulo: diagnóstico e perspectivas para a melhoria da qualidade sócio-
}

\section{ambiental}

\author{
Aspects of water quality and basic sanitation in a rural settlement in the state of São Paulo: \\ diagnosis and perspectives for the improvement of the socio-environmental quality \\ Aspectos de la calidad del agua y el saneamiento básico en un asentamiento rural del estado de São
}

Paulo: diagnóstico y perspectivas para la mejora de la calidad socioambiental

Recebido: 23/01/2021 | Revisado: 24/01/2021 | Aceito: 25/01/2021 | Publicado: 01/02/2021

\author{
Júlia Barros Peroni \\ ORCID: https://orcid.org/0000-0001-9724-7963 \\ Universidade Estadual Paulista “Júlio de Mesquita Filho", Brasil \\ E-mail: julia.peroni15@gmail.com \\ Lívia Hernandes Carvalho \\ ORCID: https://orcid.org/0000-0002-2270-5541 \\ Universidade Federal do Triângulo Mineiro, Brasil \\ E-mail: livia.carvalho@uftm.edu.br \\ Lucíola Santos Lannes \\ ORCID: https://orcid.org/0000-0002-0603-4071 \\ Universidade Estadual Paulista "Júlio de Mesquita Filho", Brasil \\ E-mail: luciola.lannes@unesp.br
}

\begin{abstract}
Resumo
A garantia do provimento de água de boa qualidade é necessária às comunidades rurais e é determinante da saúde e da geração de renda destas populações. Assentamentos rurais, entretanto, vêm sendo estabelecidos no Brasil sem as devidas estruturas necessárias no que diz respeito à qualidade da água consumida e à disposição de resíduos domésticos, impactando negativamente estas comunidades. O objetivo deste estudo foi investigar alguns destes aspectos no Assentamento "União da Vitória", no município de Suzanápolis/SP. Foram realizadas entrevistas com a população acerca da percepção ambiental sobre o assunto e determinação da contaminação de coliformes fecais em água utilizada para consumo. A maior parte da população deste assentamento reside no local desde a sua fundação em 2005 e exerce majoritariamente a função agrícola em seus lotes. Entretanto, os assentados apresentam deficiência de conhecimento sobre saneamento básico. Dos 50 lotes que tiveram a água para consumo analisadas, 9\% apresentaram coliformes fecais, todos em poços do tipo cacimba, mais vulneráveis por serem rasos. Esta porcentagem é mais baixa em relação a outros assentamentos do tipo no país. Estes dados apontam para a necessidade de informar populações rurais sobre métodos adequados de construção de poços e fossas e evidenciam a necessidade de continuação do trabalho de entidades públicas e privadas de saneamento quanto à assistência aos assentados.
\end{abstract}

Palavras-chave: Assentamento rural; Coliformes fecais; Percepção ambiental.

\begin{abstract}
The provision of potable water is needed in rural settlements and determines health and income in such populations. However, rural settlements have been established in Brazil without the needed structures to guarantee quality water and proper residues disposal, which may negatively impact these communities. The aim of this study was to investigate some of these aspects in the rural settlement "União da Vitória", in the municipality of Suzanápolis/SP. Structured interviews assessing the community environmental perception on water quality and basic sanitation were performed, as well as the determination of faecal coliforms in the water consumed by the population was done. The majority of the population lives in the settlement since its foundation in 2005 and work exclusively in their land as farmers but have deficient information regarding basic sanitation. Out of the 50 sampled farms, $9 \%$ consumed water contaminated with faecal coliforms, all found in shallow water wells, which are more vulnerable to contamination than deeper water wells. This percentage is far lower than in other rural settlements found throughout Brazil. These data point out to the need to inform this population about adequate methods for the construction of water and sewage wells and outline the necessity of this population to be assisted by public and private sanitation entities in Brazil.
\end{abstract}

Keywords: Rural settlement; Faecal coliforms; Environmental perception. 


\section{Resumen}

Asegurar el suministro de agua de buena calidad es necesario para las comunidades rurales y es un factor determinante de la salud y la generación de ingresos de estas poblaciones. Los asentamientos rurales, sin embargo, se han establecido en Brasil sin las estructuras necesarias en cuanto a la calidad del agua consumida y la disposición de los desechos domésticos, impactando negativamente a estas comunidades. El objetivo de este estudio fue investigar algunos de estos aspectos en el Asentamiento "União da Vitória", en la ciudad de Suzanápolis/SP. Se realizaron entrevistas con la población sobre la percepción ambiental sobre el tema y determinación de contaminación de coliformes fecales en agua utilizada para consumo. La mayoría de la población de este asentamiento ha vivido en la zona desde su fundación en 2005 y ejerce principalmente la función agrícola en sus parcelas. Sin embargo, los colonos carecen de conocimientos sobre saneamiento básico. De los 50 lotes en los que se analizó el agua potable, el $9 \%$ presentaba coliformes fecales, todos en pozos del tipo cacimba, que son más vulnerables por ser poco profundos. Este porcentaje es menor en relación a otros asentamientos similares en el país. Estos datos apuntan a la necesidad de informar a las poblaciones rurales sobre los métodos adecuados para construir pozos y pozos y resaltan la necesidad de que las entidades públicas y privadas sigan trabajando para ayudar a los colonos.

Palabras clave: Asentamiento rural; Coliformes fecales; Percepción ambiental.

\section{Introdução}

Toda atividade antrópica pode acarretar desequilíbrios no sistema natural do ambiente, podendo causar efeitos danosos à qualidade de vida humana e animal (Santana, 2014). Como as atividades humanas são responsáveis por gerar recursos para subsidiar o desenvolvimento econômico e social das populações, estas devem ser mantidas sempre que possível. Dessa forma, é necessário que algumas medidas sejam tomadas visando minimizar estes efeitos antrópicos sobre o ambiente de forma a conciliar a coexistência da atividade humana com conservação ambiental e saúde da população. Uma das medidas mais usuais e muito importante nesse sentido é a garantia do saneamento básico e da qualidade da água (Oliveira et al., 2017).

O saneamento básico e a qualidade da água são determinantes da saúde de qualquer comunidade humana (Araujo et al., 2020), constituindo-se assim fatores de fundamental importância para a garantia da qualidade de vida das pessoas. Saneamento básico é definido no Brasil por quatro serviços, sendo estes o esgotamento sanitário, a gestão de resíduos sólidos, o manejo de águas pluviais e o abastecimento de água potável (Brasil, 2007). O controle e vigilância da qualidade da água para consumo humano, bem como seu padrão de potabilidade, são definidos pela Portaria de Consolidação $\mathrm{n}^{\circ} 05$ (Brasil, 2017). Segundo esta legislação, cabe ao Ministério da Saúde o controle e a vigilância da qualidade da água para consumo humano, a qual é definida como “água potável destinada à ingestão, preparação e produção de alimentos e à higiene pessoal, independentemente da sua origem" (Brasil, 2011), estando incluída, portanto, água consumida em zona rural oriunda de poços de qualquer natureza. Diversos são os parâmetros a serem determinados para a conferência da potabilidade da água, dentre eles está a ausência de coliformes fecais (Brasil, 2017).

Globalmente, $80 \%$ de toda a água residual são lançadas no ambiente sem tratamento prévio adequado (UNESCO, 2019), contribuindo para a situação de que quase 2 bilhões de pessoas usam fontes de água de abastecimento contaminadas com fezes, colocando-as em risco de contraírem diversas doenças, dentre as quais podem ser citadas cólera, disenterias, tifo e poliomielite. Não pode ser ignorado o fato de que o destino correto da água residual será imprescindível para sustentar a alta na demanda crescente por água para consumo humano, industrial e agrícola (ONU, 2020). Segundo dados da Organização Mundial da Saúde, $80 \%$ das doenças que ocorrem em países em desenvolvimento são oriundas de contaminação da água. Ainda, 15 milhões de crianças de 0 a 5 anos morrem a cada ano devido à falta ou deficiência dos sistemas de abastecimento de água e tratamento de esgotos (CETESB, 1996). Os agravos à saúde em grupos sociais podem ser consequências de fontes de contaminação ambiental, da dispersão ou concentração de agentes de risco, da exposição da população a estes agentes e das características de suscetibilidade destes grupos (Corvalan et al., 1996).

Uma orientação principal constante no Relatório Mundial das Nações Unidas para o Desenvolvimento Hídrico (UNESCO, 2019) é a promoção de acesso equitativo à água para a produção agrícola. O investimento neste aspecto pode fazer 
a diferença entre a agricultura como meio de sobrevivência das famílias agricultoras e a agricultura como uma fonte confiável de subsistência, uma vez que 3/4 das pessoas vivendo em extrema pobreza no mundo residem em zonas rurais. Segundo este relatório, a vasta maioria dessas pessoas de baixa renda vivendo em zonas rurais é composta por agricultores familiares e constituem a espinha dorsal da cadeia de suprimentos alimentícios, contribuindo com mais da metade da produção agrícola em muitos países - e eles mesmos sofrem com insegurança alimentar e subnutrição. Segundo o Censo Agropecuário de 2017, levantamento realizado em aproximadamente 5 milhões de propriedades rurais no Brasil, 77\% dos estabelecimentos agrícolas do país são classificados como de agricultura familiar, empregando mais de 10 milhões de pessoas e sendo responsáveis por $23 \%$ da produção agrícola total no Brasil (IBGE, 2019).

Segundo o Sistema Nacional de Informações sobre Saneamento (SNIS), a maioria dos municípios do Brasil possui atendimento total de água maior que $80 \%$, de maneira que a maior parte dos municípios considerados no estudo se encontra próximo à universalização deste serviço. De todos os municípios do Brasil, $72 \%$ apresentam coleta de esgoto e $54 \%$ de todo o esgoto produzido no Brasil são tratados (Brasil, 2019). Em zonas rurais, entretanto, o saneamento caminha em velocidade inferior às áreas urbanas, por toda a complexidade do baixo adensamento de pessoas tornando menos viável a construção das tradicionais redes de coleta e tratamento.

Famílias residentes em assentamentos rurais oriundos da Política Pública de Reforma Agrária do Governo Federal, e implantados com a pressão do Movimento dos Trabalhadores Rurais Sem Terra (MST) vivem, em maioria, sob condições precárias de abastecimento de água e saneamento básico. Na região de Andradina/SP todos os 46 assentamentos do MST se apresentam como locais sem água encanada, sendo comum o abastecimento através de poço ou cacimba construídos pelos proprietários dos lotes, de forma rústica sem elementos básicos que protejam a água de potenciais fontes de contaminação. A principal fonte de descarte de objetos se dá em fossas negras (Carvalho, 2013). No Brasil um dos grandes desafios rumo ao alcance do desenvolvimento sustentável nas políticas de reforma agrária está relacionado ao uso e à qualidade da água nos assentamentos rurais. Definir qual é a melhor política de saneamento para uma determinada comunidade deve envolver um levantamento de informações teórico-práticas pertinentes ao tema visando pormenorizar a relação entre saneamento e ambiente. Para tanto é importante investigar a visão dos assentados com respeito à utilização dos mananciais, tanto superficiais quanto os subterrâneos, em toda a área dos assentamentos.

Uma das dificuldades para proteção dos ambientes naturais está na existência de diferenças nas percepções dos valores e da importância dos mesmos entre indivíduos de culturas diferentes. Em assentamentos rurais do MST é comum que os assentados tenham origens diversas (Soares \& Lannes, 2015), trazendo consigo percepções também diversas acerca do ambiente natural (Zinga, 2004). Entender como a comunidade assentada percebe a questão do saneamento básico e do ambiente em que vivem, em especial no que tange os recursos da região, bem como visualizar quais são suas insatisfações e perspectivas diante o fato de que aquela se encontra constantemente alterando o meio com o intuito de sanar suas necessidades, são importantes para a conservação dos recursos naturais e para a sensibilização no que diz respeito aos problemas ambientais da região em que se insere. Neste contexto, a questão do saneamento nos assentamentos rurais deve ser tratada de forma a levar em consideração as condições do saneamento no assentamento, informações a respeito da comunidade assentada e sua visão sobre o ambiente em que a circunda (Soares \& Lannes, 2015). Estas informações devem servir como subsídios para projetos eficazes de educação ambiental e sanitária nos assentamentos.

Este trabalho tem como objetivo o levantamento da atual conjuntura dos moradores do Assentamento MST "União da Vitória" na cidade de Suzanápolis, interior de São Paulo, em relação a aspectos relacionados ao saneamento básico e à percepção ambiental destes em relação ao saneamento e recursos naturais, com a intenção de buscar meios que possibilitem o estabelecimento de melhores relações entre ocupação territorial, saneamento básico e saúde humana. O principal foco do trabalho foi a verificação da contaminação por coliformes fecais do aquífero subterrâneo do Assentamento "União da Vitória". 
Além disso, visou-se analisar a percepção ambiental dos assentados em relação a condições sanitárias e a recursos naturais da região. A partir dos dados gerados, visou-se elaborar um plano de ação com o objetivo de discutir com a comunidade (infantil e adulta) sobre saneamento básico e ambiental, abordando assuntos como doenças transmitidas pela água, regras básicas de construção de poços e fossas, preservação dos recursos naturais e dúvidas decorrentes destes assuntos.

\section{Metodologia}

O assentamento "União da Vitória" foi criado em 2005 e localiza-se no município de Suzanápolis, interior de São Paulo, contando, com aproximadamente 155 famílias em lotes de 12 ha (Carvalho, 2013). O abastecimento de água local se dá por meio de poços artesianos (poços profundos com água jorrada espontaneamente devido à pressão), semi-artesianos (poços profundos com retirada de água com auxílio de equipamento de bombeamento) e cacimbas (poços rasos que captam a água superficial do lençol freático) coletivos e individuais. Os dejetos da atividade doméstica são geralmente depositados em fossas negras, sendo que estas localizam-se próximas aos poços acima mencionados (Carvalho, 2013).

O presente projeto foi realizado em 2015 e dividido em três partes principais. A primeira parte do projeto consistiu na realização da pesquisa de campo qualitativa (Pereira et al., 2018) com 50 famílias que se dispuserem a participar e colaborar. Para coletar as informações necessárias, foi aplicado um questionário contendo perguntas abertas e fechadas relativas ao saneamento básico, às condições socioeconômicas, ao tempo de permanência dos assentados no lote e à percepção ambiental dos mesmos. Mais especificamente, as variáveis acessadas junto à população foram: tempo de residência no lote, origem da família (urbana ou rural), origem da água para consumo humano, tipos de interferências dos órgãos públicos com relação à utilização dos recursos ambientais e estado de conhecimento sobre doenças transmitidas pela água. A escolha dos lotes foi de feita de forma aleatória dentre as famílias que se dispuseram a participar do projeto, totalizando 50 lotes de um total de 155.

A segunda parte do projeto foi definida pela determinação de coliformes fecais em água dos poços de água para consumo humano. Na legislação brasileira, os coliformes fecais são utilizados como padrão para qualidade microbiológica de água destinada a abastecimento, recreação, irrigação e piscicultura (CETESB, 2019; Sampaio et al., 2019). Foi coletada uma amostra por poço em cada um dos 50 lotes e determinada a presença de coliformes fecais. Quando necessário fez-se a desinfecção da bomba deixando a água escorrer antes das coletas. Em poços cacimba sem bombas, a amostragem foi feita diretamente do poço, logo abaixo da superfície, evitando a contaminação com espuma ou com o material das paredes do poço (CETESB, 1996). A análise for realizada por meio do kit microbiológico Colipaper, cartela com meio de cultura em forma de gel desidratado que quantifica a presença de coliformes fecais (Zan et al., 2012).

Por fim, a terceira fase do projeto se deu com o desenvolvimento de oficinas didáticas com o público adulto e infantil na comunidade. Elaborou-se uma cartilha ilustrada com conteúdos relacionados à pesquisa, com o objetivo de elucidar dúvidas e dificuldades mais comuns sobre saneamento básico e ambiental. Esta foi direcionada ao público infantil, desenhada em linhas pretas, reproduzidas por meio de fotocópias e dobradas em formato A5 para colorir. A cartilha foi trabalhada após uma palestra voltada para a população adulta do assentamento. A palestra abordou temas como doenças transmitidas pela água e como evitá-las, regras básicas a serem seguidas durante o processo de construção de poços e fossas, de forma garantir a potabilidade da água para consumo humano e métodos simples de descontaminação da água, como a fervura.

\section{Resultados e Discussão}

Oitenta por cento das famílias investigadas no Assentamento Rural "União da Vitória" são de origem rural, enquanto $20 \%$ são de origem urbana. Em média, cada lote possui 2 residentes e uma renda média de R $1.234,40$ reais por mês. 
Figura 1 - "Desde quando reside no assentamento?”, pergunta sobre o tempo de residência no assentamento. N=50.

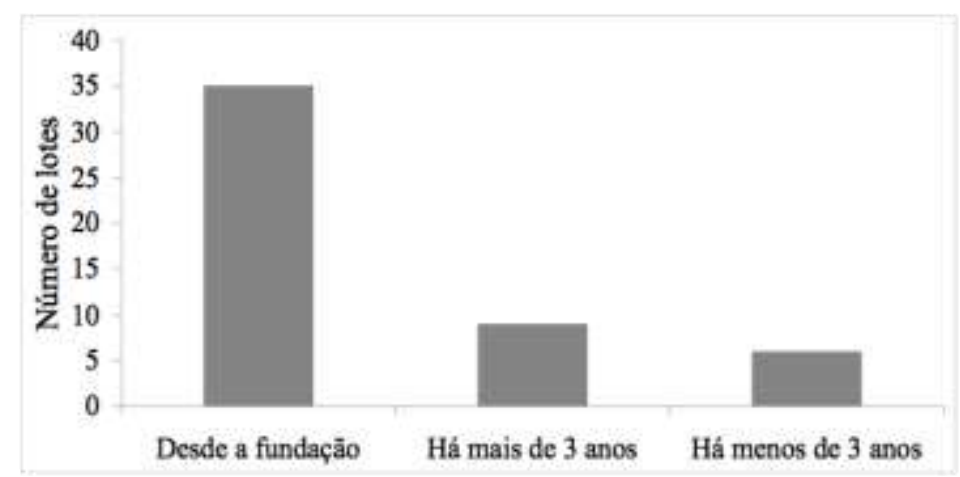

Fonte: Autores.

Figura 2 - "Qual é o tipo de escola?", pergunta sobre qual tipo de escola os filhos dos entrevistados frequentam ou freqüentaram. $\mathrm{N}=50$.

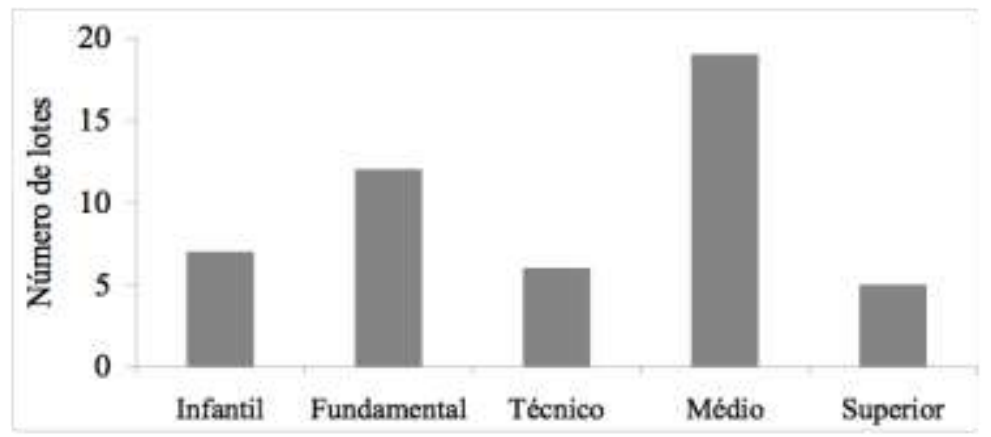

Fonte: Autores.

Setenta por cento dos entrevistados residem lá desde a fundação do Assentamento, em 2005 (Figura 1). A maioria dos estudantes residentes nos lotes amostrados concluiu ou está cursando o último ano do Ensino Médio, e uma pequena porcentagem está cursando ou já concluiu o Ensino Fundamental (Figura 2).

Figura 3 - “Onde fica a escola?", pergunta sobre onde está localizada a escola que os filhos dos entrevistados frequentam ou freqüentaram. $\mathrm{N}=50$.

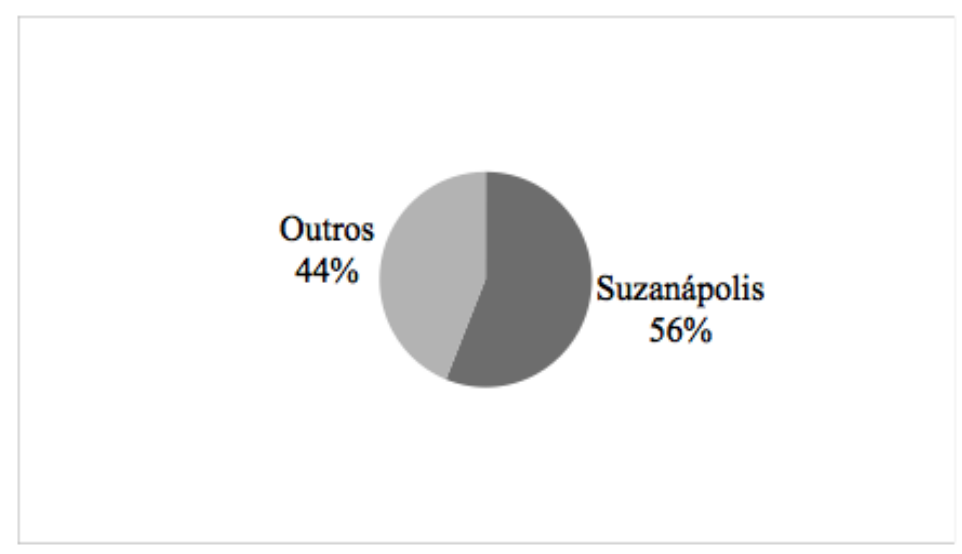

Fonte: Autores. 
Figura 4 - "Atividade profissional”, pergunta se o entrevistado exerce alguma atividade profissional fora do lote ou se realiza somente a atividade agrícola dentro do lote. $\mathrm{N}=50$.

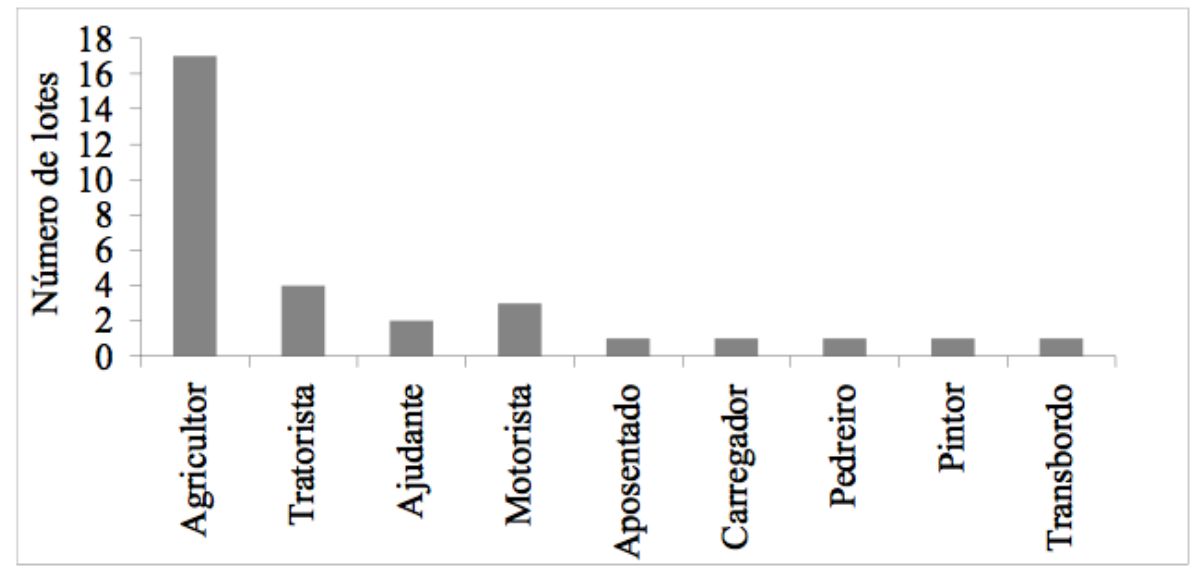

Fonte: Autores.

A maioria dos entrevistados frequenta ou frequentou as escolas de Suzanápolis - SP (Figura 3) e trabalha dentro do lote, sendo poucos os moradores que exercem atividades fora do Assentamento (Figura 4).

Tabela 1 - Sintomas de algumas doenças apresentadas, nos últimos 3 meses, pelos entrevistados no Assentamento "União da Vitória" em Suzanápolis/SP.

\begin{tabular}{cc}
\hline Sintomas & Número de lotes que apresentaram \\
Problema na coluna vertebral & 29 \\
Doença de pele & 26 \\
Náusea e vômito & 18 \\
Coceira na pele & 11 \\
Dor abdominal & 10 \\
Diarréia & 9 \\
Depressão & 9 \\
Dores corpo e na cabeça & 7 \\
Pressão alta & 7 \\
Verminose & 7 \\
Doença “de nervo" & 5 \\
Febre & 5 \\
Outros & 9 \\
\hline
\end{tabular}

Fonte: Autores.

Observou-se que 58\% dos entrevistados necessitam de algum tipo de acompanhamento médico constante, tendo sido observada a presença de sintomas como dores na coluna, diarreia, verminoses, pressão alta, dores abdominais, febre, dores no 
corpo ou de cabeça, náuseas e vômito, coceiras na pele, doenças de pele, doença “de nervo" e depressão (Tabela 1) nos últimos três meses anteriores à investigação.

Figura 5 - “Qual é a principal produção do lote?”, pergunta sobre que tipos de produto o lote produz.

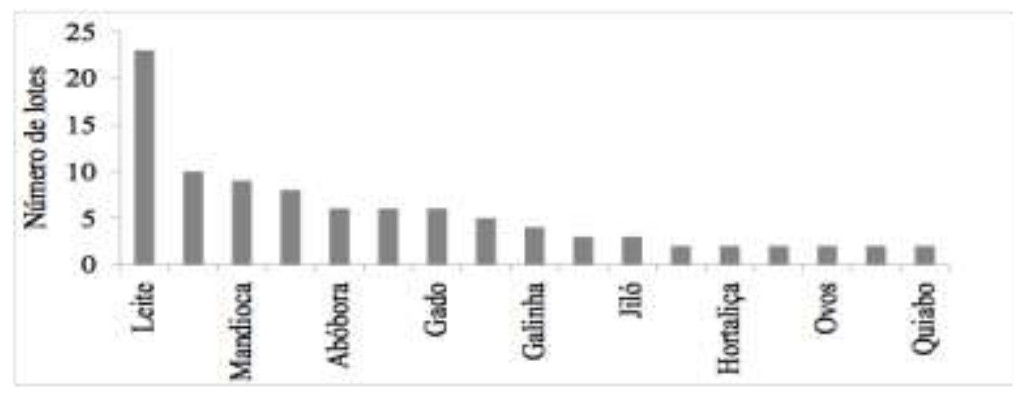

Fonte: Autores.

A principal produção dos lotes entrevistados é o leite seguido por pepino, mandioca, milho, batata, abóbora, gado de corte, feijão, pimenta, galinha, berinjela, jiló, maracujá, ovos, porco, banana, quiabo e hortaliças (Figura 5). Com tamanha diversidade de produtos, poucos entrevistados não utilizam adubo, sendo que a maioria utiliza adubos químico e orgânico e pesticidas (herbicidas e inseticidas) na plantação.

A água é um recurso natural essencial à sobrevivência de todos os seres vivos, sendo sua qualidade e potabilidade fatores indispensáveis para seu consumo de forma segura à saúde. Um fator determinante à qualidade da água é a preservação ambiental, principalmente ao redor das nascentes, dos rios e dos poços que abrigam esse recurso tão importante à vida, para evitar que o próprio ambiente a contamine. Isso mostra que para haver qualidade de vida humana o ambiente deve apresentar. Esses aspectos passaram a ser levados em consideração pouco tempo atrás, pois durante as pesquisas sanitárias eram apenas considerados os aspectos da qualidade de vida humana.

Figura 6 - "Qual é a origem da água para beber?”, pergunta sobre de onde vem a água para consumo humano. N=50.

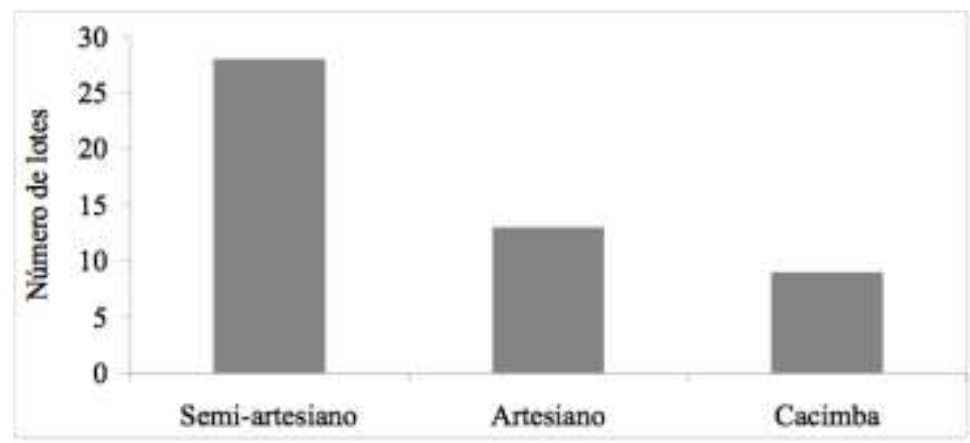

Fonte: Autores. 
Figura 7 - “O núcleo possui algum tipo de tratamento da água?”, pergunta sobre algum tipo de tratamento caseiro utilizado para tratar a água antes do consumo.

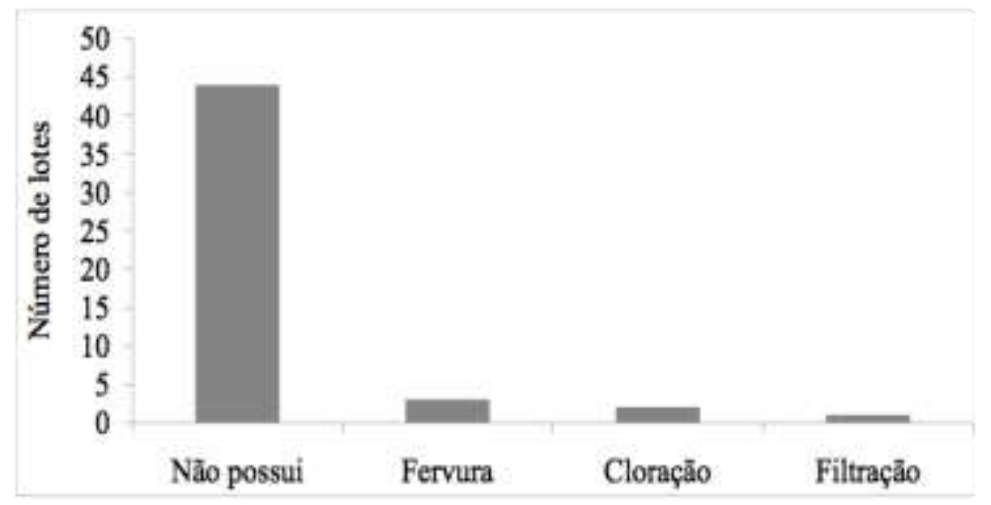

Fonte: Autores.

A principal fonte de água para consumo humano nos lotes do Assentamento "União da Vitória" é advinda de poços semi-artesianos seguido por poços artesianos instalados pelo INCRA (Figura 6) e por último os poços-cacimba, sendo que na a água nunca havia sido analisada quanto à presença de coliformes fecais. Em quase todos os casos a água não recebe tipo algum de tratamento como fervura ou cloração (Figura 7), conforme também observado em outro assentamento próximo ao "União da Vitória" (Dornfeld et al., 2018). Estes dados concordam com os de Carvalho (2013), que verificou que 67\% das famílias também consomem a água in natura e 32\% fervem ou cloram a água antes de consumi-la nos Assentamentos da região da Andradina, como é o caso do Assentamento "União da Vitória”.

A distribuição de água entre as zonas rurais e urbanas é de forma desigual, pois o abastecimento de água nas zonas urbanas é feito por meio de rios e mananciais, já nas zonas rurais é feito por meio de poços artesianos, semi-artesianos, cacimbas, entre outros, sendo estes mais passiveis de contaminação por agentes microbiológicos advindos de esgotos domésticos (Mattos \& Soares, 2015).

Figura 8 - "Qual é a qualidade da água para consumo humano? ", pergunta sobre a opinião do entrevistado em relação à qualidade da água para consumo humano. $\mathrm{N}=50$.

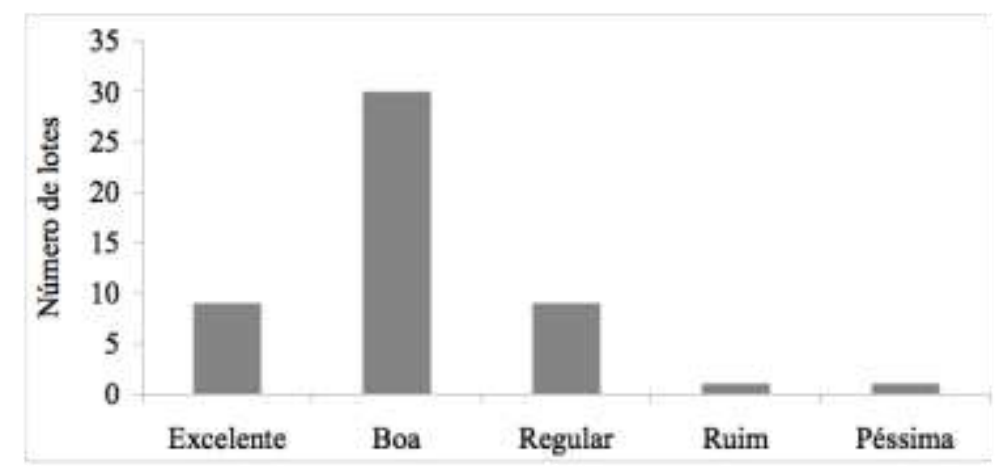

Fonte: Autores. 
Figura 9 - "Qual é o tipo de fossa utilizada no lote? “, pergunta sobre onde são depositados os dejetos domésticos. N=50.

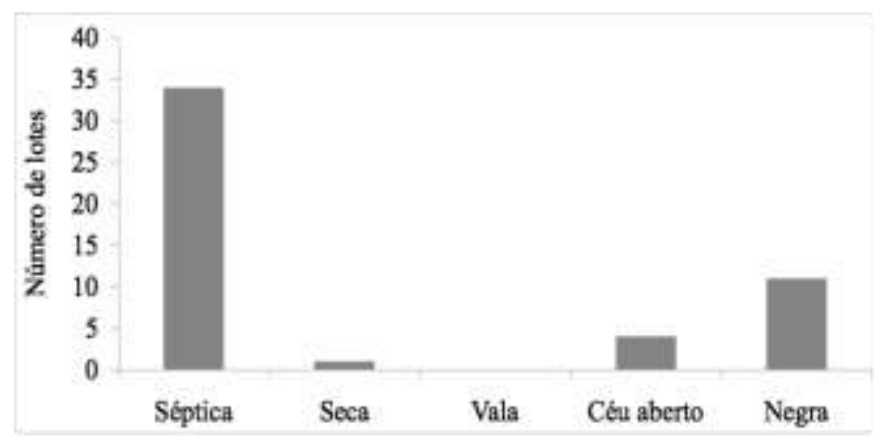

Fonte: Autores.

Figura 10 - "Recebe alguma orientação de órgão e/ou instituição pública com relação ao saneamento básico?”, pergunta sobre orientação acerca de saneamento básico advinda do poder público. $\mathrm{N}=50$.

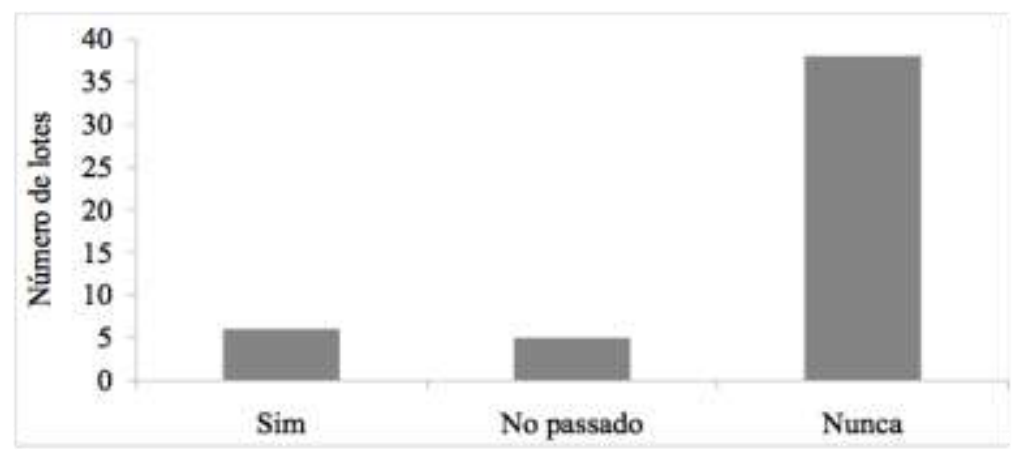

Fonte: Autores.

Figura 11 - "Realiza alguma atividade junto aos recursos hídricos da região?”, pergunta sobre a utilização dos corpos d'água adjacentes pelos moradores dos lotes. $\mathrm{N}=50$.

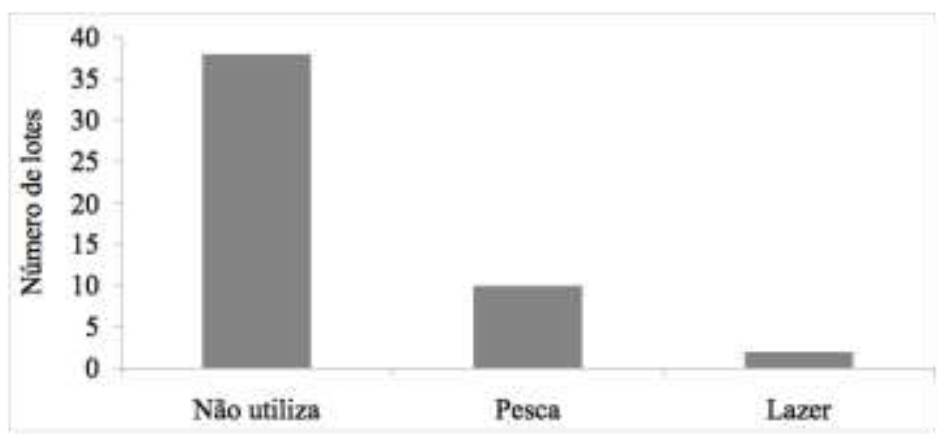

Fonte: Autores.

Observou-se que mesmo a água não sendo de origem encanada e tratada, a maioria dos entrevistados considera a água para consumo humano de boa ou de excelente qualidade e apenas poucos dos entrevistados a consideram ruim ou de péssima qualidade (Figura 8). Os dejetos domésticos são prioritariamente despejados em fossas sépticas, ao contrário de outros assentamentos, onde principal destino do esgoto são as fossas negras (Holgado-Silva et al., 2014) (Figura 9). Segundo observado no local, as fossas negras, fossas secas e as áreas de esgoto a céu aberto estão localizadas em média a 30 metros do poço, em uma distância bem acima dos 15 metros, estabelecido como seguro (Chaves et al., 2010). As fossas sépticas foram 
instaladas recentemente no Assentamento "União da Vitória” pela Prefeitura de Suzanápolis juntamente com o INCRA. Mesmo recebendo esse tipo de apoio da Prefeitura e do INCRA nesse sentido, $76 \%$ dos entrevistados informaram que nunca receberam orientações técnicas sobre saneamento básico e saúde (Figura 10). Foi observado, também, que poucos dos entrevistados utilizam os recursos hídricos da região para pesca e lazer (Figura 11).

Em decorrência dessa carência de informações, observou-se que apenas $36 \%$ dos entrevistados conhecem alguma doença transmitida através da água, sendo estas: verminose, dengue, hepatite, doenças de pele e diarreia. Como mencionado anteriormente, a Prefeitura de Suzanápolis dá suporte à comunidade assentada em relação a algumas questões de saneamento, porém a maioria dos entrevistados acredita que esta (ou outro órgão) deveria dar mais atenção ao assentamento em relação a informações concernentes ao saneamento básico.

Figura 12 - Resultados dos testes para presença de coliformes fecais na água utilizada pela população do Assentamento "União da Vitória” em Suzanápolis/SP. N=50.

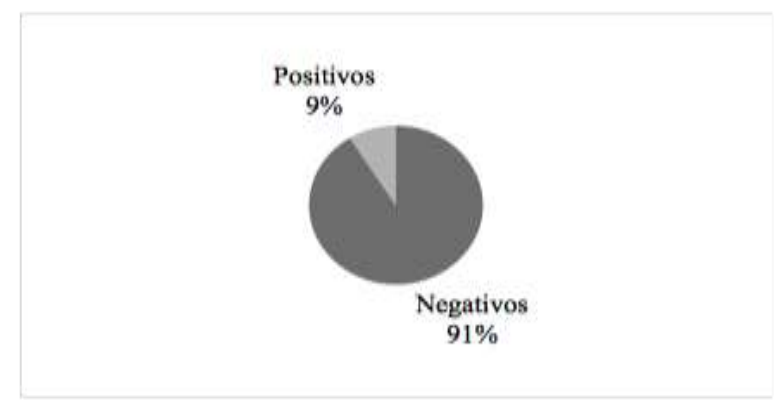

Fonte: Autores.

Alguns estudos mostram que as fezes do homem e animais de sangue quente contêm grande quantidade de bactérias do tipo coliforme e que estas podem estar presentes no solo e em plantas, mas não estão presentes em água não poluída (CETESB, 1996). As análises microbiológicas da água demonstraram que somente $9 \%$ dos poços apresentam coliformes fecais (Figura 12), estando, portanto, fora dos padrões microbiológicos aceitáveis de potabilidade e por isso encontram-se inapropriadas para o consumo. De acordo com a legislação brasileira que dispõe sobre a qualidade microbiológica da água para consumo humano no Brasil, água potável deve ser livre de coliformes fecais (Brasil, 2011; Brasil, 2017). Ressalta-se que todos os poços contaminados são do tipo cacimba. Estes resultados vão de encontro a outros assentamentos rurais no Rio de Janeiro (Soares \& Lannes, 2015), no Paraná (Abonizio, 2017; Cadoná, 2017) e até mesmo em outros próximos à área de estudo (Dornfeld et al., 2018), onde a maioria dos lotes apresentou contaminação por coliformes fecais. Estas diferenças evidenciam que as questões sociais e sanitárias rurais devem ser avaliadas e tratadas caso-a-caso, dada a heterogeneidade e complexidade das mesmas em diferentes regiões do Brasil (Nogueira Silva et al., 2016).

Com o avanço das pesquisas e das exigências no padrão de qualidade da água para consumo humano é possível notar um aumento nas pesquisas de em relação à qualidade microbiológica, segundo o que diz o Ministério da Saúde na Portaria $\mathrm{N}^{\circ}$ 2.914 “Art. $3^{\circ}$ Toda água destinada ao consumo humano, distribuída coletivamente por meio de sistema ou solução alternativa coletiva de abastecimento de água, deve ser objeto de controle e vigilância da qualidade da água” (Brasil, 2011). 
Figura 13 - Palestra sobre Saneamento Básico e Qualidade da Água, ministrada no Assentamento "União da Vitória" no último dia do projeto.

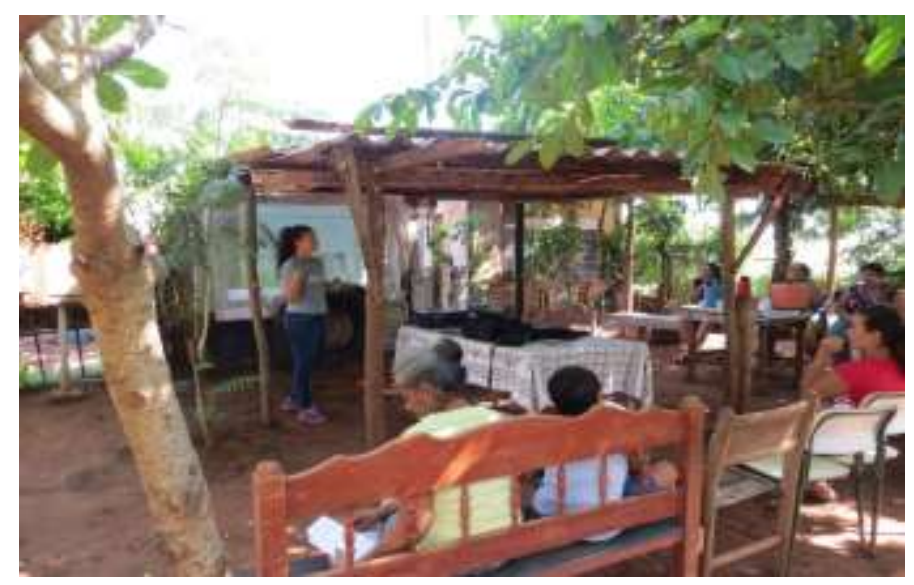

Fonte: Autores.

Figura 14 - Cartilha para colorir contendo informações sobre saneamento básico e qualidade da água distribuída às crianças presentes durante a palestra.

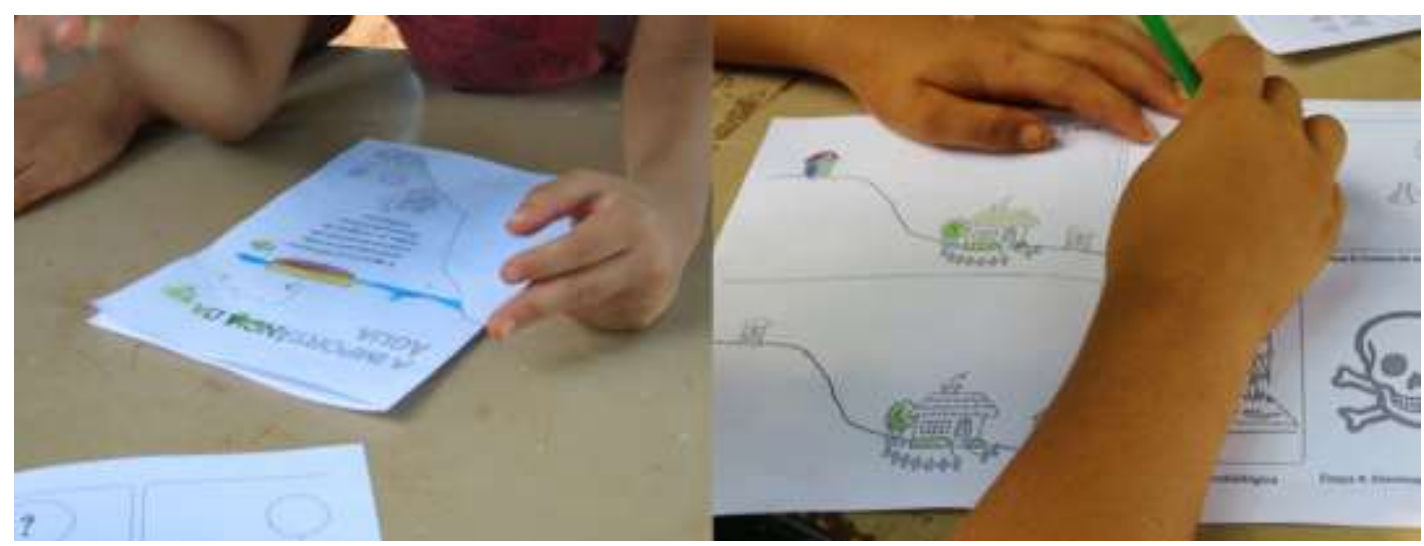

Fonte: Autores.

Com bases nos resultados obtidos, foi realizada uma oficina no dia 22 de fevereiro de 2016, no período da tarde em um dos lotes do assentamento, sendo que a maioria dos entrevistados esteve presente. A oficina iniciou-se com agradecimentos aos assentados entrevistados e aos colaboradores do projeto, logo em seguida foram apresentados os resultados das análises microbiológicas dos poços em forma de laudo, entregues individualmente para o representante do lote. As dúvidas decorrentes foram sanadas durante a palestra e ao final da apresentação (Figura 13). A palestra foi ministrada de forma a abordar aspectos concernentes à qualidade da água, fatores contaminantes, tratamento da água em pequena escala, tipos mais indicados de fossas e poços. Durante a palestra foi entregue às crianças uma cartilha para colorir (Figura 14), a qual continha informações relevantes à qualidade da água, fatores contaminantes e tratamento da água.

\section{Conclusão}

Diversas leis, tratados e relatórios obrigam e/ou sugerem que haja promoção de acesso à água de qualidade em pequenas propriedades rurais. O Assentamento Rural "União da Vitória" apresenta, em geral, boa qualidade microbiológica da água consumida, podendo servir como bom exemplo para outros assentamentos rurais nesse sentido. Entretanto, o atual conhecimento dos assentados entrevistados em relação ao saneamento básico é deficiente devido à carência de informações 
advindas de órgãos responsáveis por orientar a população sobre assuntos sanitários. É notória a preocupação dos entrevistados com a qualidade da água para consumo humano e irrigação agrícola, sendo observada durante a palestra ministrada no assentamento, por isso espera-se que a população siga as instruções dadas durante a palestra no evento final do projeto, evitando assim doenças que possam ser causadas por bactérias de veiculação hídrica.

É recomendada a realização de estudos da mesma natureza em outros Assentamentos em diferentes regiões brasileiras para explorar a existência de relação entre a localização geográfica dos Assentamentos e os efeitos da qualidade da água sobre a situação sanitária dos lotes bem como sobre a percepção ambiental dos assentados em relação aos recursos naturais das regiões em que vivem.

\section{Agradecimentos}

Este trabalho foi realizado com o auxílio e acolhimento do senhor Paulo Francisco dos Santos Gonçalves e da senhora Telma Maria da Silva, do Assentamento "União da Vitória", aos quais agradecemos pela colaboração contínua, dedicação e empenho junto às famílias residentes no Assentamento para a obtenção dos dados apresentados na presente pesquisa.

\section{Referências}

Abonizio, R. M. (2017). Saneamento básico no meio rural: um estudo em assentamento rural no interior do Paraná. 60p. Trabalho de Conclusão de Curso (Bacharelado em Engenharia Ambiental) - Universidade Tecnológica Federal do Paraná, Campo Mourão.

Araujo, B. M., Santos, A. S. P., Pavan, F. \& Melo, M. C. (2020). Instrumentos informativos de educação ambiental e sanitária aplicados na sociedade. Perspectivas Online: Humanas \& Sociais Aplicadas, 10 (27), 33-45.

Brasil, Ministério do Desenvolvimento Regional. Secretaria Nacional de Saneamento - SNS. (2019). Sistema Nacional de Informações sobre Saneamento: $24^{o}$ Diagnóstico dos Serviços de Água e Esgotos 2018. SNS/MDR. Diário Oficial da República Federativa do Brasil.

Brasil, Ministério da Saúde, Portaria de Consolidação no 5 de 28 de setembro de 2017. (2017). Dispõe sobre a consolidação das normas sobre as ações e os serviços de saúde do Sistema Único de Saúde. Diário Oficial da República Federativa do Brasil.

Brasil, Ministério da Saúde, Portaria $\mathrm{n}^{\circ} 2.914$ de 12 de dezembro de 2011. (2011). Dispõe sobre os procedimentos de controle e de vigilância da qualidade da água para consumo humano e seu padrão de potabilidade e dá outras providências. Diário Oficial da República Federativa do Brasil.

Brasil. Lei no 11.445, de 05 de janeiro de 2007. (2007). Estabelece diretrizes nacionais para o saneamento básico. Diário Oficial da República Federativa do Brasil.

Brasil, Ministério da Saúde. Portaria n ${ }^{\circ}$ 36, de 19 de janeiro de 1990. (1990). Altera a portaria de no 56/1977. Diário Oficial da República Federativa do Brasil.

Cadoná, M. R. (2017). Saneamento básico: Estudo de caso no assentamento rural Nossa Senhora Aparecida, Mariluz, Paraná. 54p. Trabalho de Conclusão de Curso (Bacharelado em Engenharia Ambiental) - Universidade Tecnológica Federal do Paraná, Campo Mourão.

Carvalho, L. H. (2013). As condições de vida dos assentados da região de Andradina: a realidade e os indicadores de avaliação da política pública de reforma agrária. 228p. Tese (Doutorado em Serviço Social) - Universidade Estadual Paulista - UNESP, Franca.

CETESB, Apêndice E. (2016). Significado Ambiental e Sanitário das Variáveis de Qualidade das Águas e dos Sedimentos e Metodologias Analíticas e de Amostragem. Manual técnico. São Paulo.

CETESB. (1996). Técnicas de análise microbiológica da água: tubos múltiplos. Manual técnico. São Paulo.

Chaves, J. R, Rolim, H. O., Santos, E. V. M. \& Filho, H. A. S. (2010). Características gerais dos sistemas locais de esgotamento sanitário de Miguel Pereira, Russas - CE. In: Congresso Norte Nordeste De Pesquisa E Inovação, 2010. Anais: Connepi.

Corvalan, C., Briggs, D, Kjellstrom, T. (1996). Development of environmental health indicators. In: Linkage methods for environment and health analysis (D. Briggs, C. Corvalan, M. Nurminen, eds.), Genebra: OMS.

Dornfeld, C. B., Leite, M. A., Marostica, M. S., Queiroz, T. V., Ferreira, E. M. S. \& Martins. F. L. (2018). Saneamento básico e questões ambientais em assentamento rural no noroeste paulista. Saúde e Meio Ambiente, 7 (2), 3-21.

Holgado-Silva, H. C., Padua, J. B., Camilo, L. R. \& Dorneles, T. M. (2014). A qualidade do saneamento ambiental no assentamento rural Amparo no município de Dourados-MS. Revista Sociedade \& Natureza, 26 (3), 535-545.

IBGE. (2019). Instituto Brasileiro de Geografia e Estatística. Censo Agropecuário - Resultados Preliminares. Rio de Janeiro, 8, 1-105.

Mattos, N. S. \& Soares, F. M. P. (2015). Análise microbiológica da água do Assentamento rural de Promissão. Mostra Acadêmica da UNIMEP. 
Research, Society and Development, v. 10, n. 2, e1010212293, 2021

(CC BY 4.0) | ISSN 2525-3409 | DOI: http://dx.doi.org/10.33448/rsd-v10i2.12293

Nogueira Silva, E., Firmino do Amaral, R. \& Matos Maciel, H. (2016). Campesinato e Reforma Agrária: Um debate contemporâneo. Perspectivas Online: Humanas \& Sociais Aplicadas, 15 (6), 1-13.

Oliveira, C. M. (2017). Sustainable access to safe drinking water: fundamental human right in the international and national scene. Revista Ambiente \& Água, $12(6), 985-1000$.

ONU. (2020). Water quality and wastewater. Manual técnico. Genebra.

Sampaio, C. A. P., Ide, G. M., Batalha, C. P., Pereira, L. C. \& Bueno, L. F. (2019). Análise técnica de água de fontes rurais. Engenharia Sanitária e Ambiental, 24 (2), 213-217.

Pereira, A. S., Shitsuka, D. M., Parreira. F. J., Shitsuka, R. (2018). Metodologia da pesquisa científica. UAB/NTE/UFSM.

Santana, A. T. (2014). Estudo da qualidade da água para consumo humano em assentamentos de Teodoro Sampaio - SP. 101p. Dissertação (Mestrado em Meio Ambiente e Desenvolvimento Regional) - Universidade do Oeste Paulista, Presidente Prudente.

Soares, G. F. \& Lannes, L. S. (2015). Saneamento básico e assentamento rural - um estudo de caso do Assentamento Zumbi dos Palmares, RJ. Perspectivas Online: Biológicas \& Saúde, 13 (4), 44-58.

UNESCO. (2020). World Water Assessment Programme. 2019. The United Nations World Water Development Report 2019: Leaving No One Behind. Manual técnico, Paris.

Zan, R. A., Costa, A. L., Costa, J. B. \& Meneguetti, D. U. O. (2012). Análise microbiológica de amostras de água em poços rasos localizados no município de Buritis, região do vale do Jamari, Rondônia, Amazônia central. Revista Eletrônica em Gestão, Educação e Tecnologia Ambiental, 8 (8), $1867-1875$.

Zinga, M. R. M. (2004). Um estudo de caso sobre as causas da permanência e desistência no assentamento Zumbi dos Palmares. 120p. Dissertação (Mestrado em Políticas Sociais) - Universidade Estadual do Norte Fluminense, Campos dos Goytacazes. 